\title{
The "6R+NY" Management Model and Some Correlations
}

\author{
Antonio Clodoaldo de Almeida Neto and Nubia Moura Ribeiro \\ Salvador Campus of the Instituto Federal de Educação, Ciência e Tecnologia da Bahia (IFBA), Rua Emídio dos Santos, Barbalho, \\ Salvador, Bahia, CEP 40301-015, Brazil
}

\begin{abstract}
This paper presents the " $6 \mathrm{R}+\mathrm{NY}$ "* Management Model that includes variables and dimensions necessary to the contemporary dynamics of organizational management. This model is adherent to the PDCA (plan, do, check, action), as a management methodology widely used in organizations. The " $6 \mathrm{R}+\mathrm{NY}$ " Model exploits the evidence symbolic and mnemonic eight words that illustrate the dimensions that are the subject of management. Besides, the article seeks to show correlations between the model proposed here and other theories and concepts.
\end{abstract}

Key words: Modeling, management, management model, PDCA.

\begin{abstract}
* In Portuguese, which is the language of the authors, the model was called "8R' $s$ " Management Model as it is established under 8 Principles and Operational Aspects of Management, all started in Portuguese by the letter "R", namely: Recursos, Resultados, Rendimento, Resíduos, Relacionamento, Rede, Responsabilidade and Rapidez, respectively: Resources, Results, Yields, Residues (involved in the production or transformation process), Relationship (with stakeholders), Network (organizational information, knowledge, learning and innovation), Responsibility (environmental organizational, social, cultural and economic) and Rapidity in strategy, innovation, production and learning organizational). So, in English the Abbreviation for 8R's could be represented by "6R+NY".
\end{abstract}

\section{Introduction}

This article, based on the general systems theory and on the concepts of modeling and models, presents a management model aligned with the complex demands of modernity. According to the Stanford Encyclopedia of Philosophy [1], although there is a distinction between "model" and "modeling", the word "model" is related to these two meanings. In Latin, modellus was a measuring device, for example, a device for measuring the volume of water or milk. However, when the Latin word was translated into English, three words were generated: "mold",

Corresponding author: Antonio Clodoaldo de Almeida Neto, Ph.D., professor, research fields: management and organizational innovation, strategy, quality management, coaching. "module" and "model". In the late 17th century, the word "model" became related to the representation of real objects shape through a theory. In this sense, "modeling" would be the construction of this theory.

As the above mentioned encyclopedia, "To model a phenomenon is to construct a formal theory that describes and explains it. In a closely related sense, you model a system or structure that you plan to build, by writing a description of it. These are very different senses of 'model' from that in model theory: the 'model' of the phenomenon or the system is not a structure but a theory, often in a formal language" [1].

To Suppes, Pavel and Falmagne, "A representation of something is an image, model, or reproduction of that thing. References to representations are familiar and frequent in ordinary and scientific discourse" [2]. According to these authors, the representation normally improves our understanding of the represented object (like an architectural plan that favors the understanding of a particular building), and the use of models in science very often, by providing multiple examples of representations. "[...] representation is typically defined in the restricted sense as a description of an empirical structure in a convenient scientific language. This sense of 
representation is closely related to the concept of a model" [2].

Dye considers model as a simplified representation of some aspect of the real world [3]. Thus, model can be an actual physical representation-a prototype or model — or may be a diagram — a map or the flowchart, etc.

There are thousands types of models, in general, they are visual tools used in various fields and with various functions, such as analysis, management, communication. Flowcharts, tables, figures, graphs, equations, diagrams, concept maps are widespread examples of models used as cognitive resources to represent and describe a given situation or context, in the pursuit of understanding of the concepts used in the production and dissemination of knowledge. A simple graph " $y$ " versus " $x$ " is a model that helps us understand the relationship between two variables [4]. The use of models in our daily activities even without realizing we are using it.

"Models are mental concepts used to enable the understanding of complex situations [...]. They are used in analysis and synthesis to improve the planning conditions and reduce uncertainty in the decision-making process [...] A model is a replica or representation of an idea, of an object or of a system. A model describes approximately how a certain system behaves" [4].

Based on the above, it behooves us to note that a model that tries to reproduce a given reality is only a mental representation of it, but the model helps in compression and management the reality. The management model presented in this article is based on PDCA (plan, do, check, action) and other concepts.

\section{2. "6R+NY" Management Model}

The " $6 \mathrm{R}+\mathrm{NY}$ " Management Model introduces new variables and dimensions that worth mentioning in the dynamic organizational management. This designation makes use of the symbolic and mnemonic evidence of eight words that illustrate additional management dimensions, being fully adhered to the PDCA model that is a management methodology. The PDCA cycle is a scientific management method, synthesized in words Plan, Do, Check, Action. Thus, corresponds to the operation of the administrative activities of Planning, Doing (execution, performance), Checking (verification, evaluation) and Corrective Action (learning), by turning them to get continuous and unceasing improvement adding value to production processes and, consequently, to their products. Walter Shewhart developed this model in the 1920s and William Edward Deming popularized it from 1950 [4].

This paper indicates also the convergence of 8R's with MEM (management excellence model), present in the various awards of excellence in management. The proposed management modeling exercise emphasizes the close relationship between the management and production concepts. The production implies the use of resources (inputs), transforming them, by work (energy variation) in products, goods or services, tangible or intangible (outputs or results). Management is characterized as an act of plan, organize, direct, control, organize the production, aiming to reach the better relationship between the use of resources and the increase in results, taking into account the needs of the various participants of the production process, the so-called "stakeholders" [5].

Management and production generate different scenarios or shapes of organizations over time. These organizations necessarily are mutants and adaptive to survive and develop, modifying and feeding back to each other. Therefore, a dynamic, productive cycle is formed and it endogenously feeds itself, locating this production-consumption-organization-management cycle in a universal context. Hence, it is essential to focus on the quality of this transformation of inputs in goods, which characterizes, in fact, the production.

In Fig. 1 it is shown a systemic view of production and its relationship with the " $6 \mathrm{R}+\mathrm{NY}$ " management model, namely (R1) Results, (R2) Resources, (Y) 
Yields, (R3) Relationships, (N) Network, (R4) Residues, (R5) Responsibility, (R6) Rapidity.

From the perspective of " $6 \mathrm{R}+\mathrm{NY}$ ", illustrated in Fig. 1, Resources are transformed into Results, according to a given Yield, aimed at generating products (Goods and Services, G/S) to meet a given need of customers or users who demand these needs. To survive in the environment generator of continuous changes and challenges - that is the contemporary society—organizations need to reinvent dynamic and continuously.

From the perspective of knowledge management, organizations can be understood as a Learning Network, multifunctional interconnected webs that integrate data and information, producing improvements and innovations to make it more competitive and more suitable for long-term survival. The approach on Learning Networks rises in organizational studies. As an example, Stoker defined one Networked Governance Model (Networked
Governance, NG) [6], as a collection of decisions characterized by the tendency of a very large spectrum of participants seen as legitimate members of the decision process, in a complex and uncertain context.

The vision of the organization as a network also applies to a relationships network, where is important the management of interests (sometimes antagonist) of each part or organizational actor, the stakeholders: citizens, products users or customers, controllers of the organization (shareholders, rulers, executives), employees (servants or employees and contractors who make up the workforce) and their unions, suppliers of various resources or inputs, society (including the surrounding community and the employer market), the government agency (administrators, regulators, supervisory etc.), and even the media that often operate as inspectors. All these entities, actors with interests in productive organizational environment, have typical and authentic demands within the management and it needs answers or specific products to be supplied and

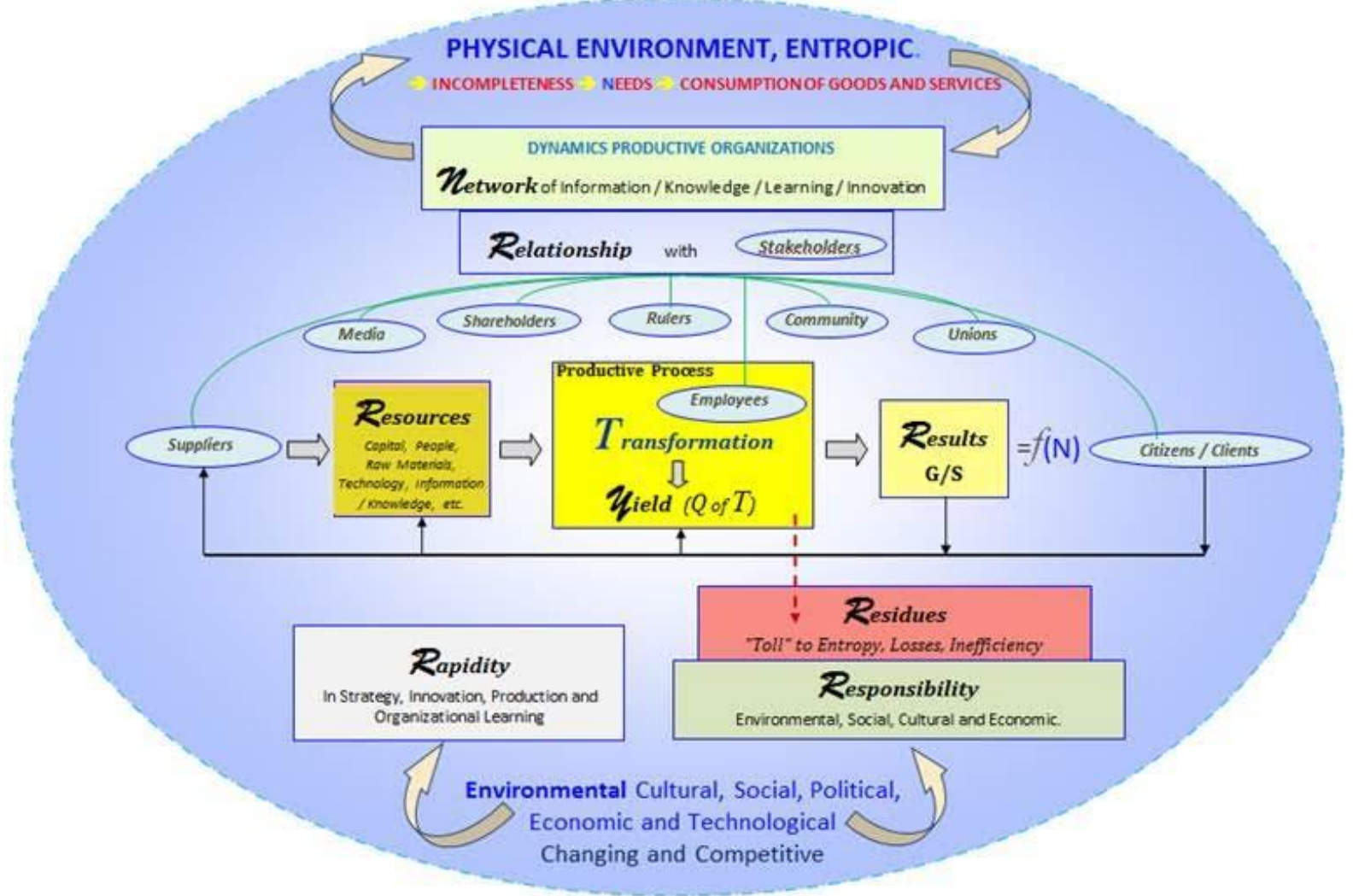

Fig. 1 A systemic vision production and management model of the eight dimensions ("6R+NY"). 
therefore managed. Both, the production processes and the management are made by people, with people and for people. Therefore, necessarily, a management process requires intensive horizontal and vertical relationships between the manager and the stakeholders involved in this organization. This relationship web is a key element in a process of management, fed by information through interaction between the parties. Managing and enhancing this variable is indispensable to a modern management of organizations.

The information flow and the relationships between the various actors involved in the production process reinforce the perspective of the organization as a Network. Every organization can be understood as a productive network, a web of multiple interactions, leading to continuing consequences, decisions, directions that result in products and services to suit any user.

Learning that all user or customer of a production process is plaintiff being, organizations systematize the production of goods and services, i.e., the Results of this production process, to meet the objective or subjective needs of this individual and supplying these needs, in short, should be the reason for any productive organization. The degree of satisfaction of the client is configured as the Benefit obtained, which returns as feedback to the production process, meaning the measurement of output Effectiveness. This finalistic focus on customers and users, public and private, must govern all management practice, synchronized and tuned with the social, economic, political, technological and environmental demands of the communities and the employer market where the organization operates. Moreover, this client, at least theoretically, has the power of choice, both in the selection of leaders, in a democracy, as the supplier, in an open and competitive economy.

In the systemic perspective presented, the results or products are effects or outputs of a process of transformation of some inputs or Resources: both natural, physical, and abstract resources. These resources can raw materials, the environment, the capital, the work of man and machine, information, knowledge, technology, energy etc.

The satisfaction degree of the stakeholders is a meaningful measure or information and should be understood as an input, feedback object on systemic productive perspective, as a whole. All these resources come in the production process and are transformed into results, goods and services to meet needs. The quality of this transformation characterizes the Yields of that production process and also deserves a special focus, needs to be well managed, since this variable is associated with the costs of the production process. Its measurement reveals the efficiency of the productive system.

From an economic point of view, the desire is to generate wealth or to add value to the resources: it is desired that the output value be greater than the input value. This relationship, in production terms, measures the productivity of this productive or organizational process, which should always be greater than 1 , i.e. the benefits value should overcome the "value" of costs. Thus, producing, in theory, would be the continuous search for improve the value of the resources.

This ability to add value, both in the production process itself, as in organizations as a whole, is measured as productivity. How resources are increasingly scarce and the expected results (associated with benefits) increasing, every business owner or manager lives on a maximum pressure, almost a mantra: "Do more with less". This pursuit of productivity, due to the rationality of the production process, presses everybody. Undeniably, it has been obtained in the course of history by adding value, by means of technology or by applying knowledge, which innovates and creates more rational forms and even innovative production. Among the technologies, news organizational management procedures can be considered one of them. 
From an organizational point of view, a structure of productive work and an approach in production management, it is essential to consider the quality of the transformation. This should be a significant variable in the productive context and can be understood as "Yields" (not in the economic sense, but rather in the physical sense) of any energy transformation machine. The "Yields" of the transformation is directly proportional to the quality of production [5].

Not all the energy that goes into the production system is transformed into useful energy, which generates work. Moreover, one cannot ignore that whole transformation process also leaves environment "Residues" of multiple orders. An energy-wasteful production process will have less yield after processing, generating, as a result, more waste. In this regard, it is appropriate to evidence and treat this issue in the economic and administrative fields [5].

Such considerations are fundamental in the creation of the " $6 \mathrm{R}+\mathrm{NY}$ " Management Model, in which the management of "Residues" and "Social Responsibility", including its environmental, cultural and economic aspects, that must be systematically and structurally managed by producer organizations, towards a sustainable future.

As we live in a changing and competitive environment, management is under heavy time pressure and cannot dissociate the compass that requires quick decisions, continuous adjustments in both its strategic process and in routine. Then, the Rapidity is a variable that needs to be administered continuously. In the world where productive organizations work, the time variable was, is and will always be fundamental.

The public sector traditionally values the variable space (desktop as a symbol of power) and, generally, consider the variable time in the bureaucratic perspective and not in the actual meeting the needs and demands of citizens and taxpayers. The business sector is highly dependent on the time, as an element of competitiveness and survival. The motto is to do, well done and quickly, before a competitor does.

In this world shaped by the ICT (information and communication technology) - a world no longer just "liquid", but "gaseous" [7] - the Rapidity became indispensable. Moreover, the new (but not always the best) demands of society pushing the productive organizations, which should result in different services as responses to different context.

New knowledge, technologies, values, habits, products, services and social, political, economic and environmental demands require new paths or upgrading the existing path speedily. This vector can go against the usual way, and sometimes, rather inertial and reactive working mode in public and private educational institutions. The speed of action, reaction or innovation must be accompanied and monitored by the CEOs at this time.

It is noteworthy that the Rapidity variable is associated with time management, while rare resource, immaterial, fluid, fundamental to today's managers. This difficulty overcomes the lack of a management properly systematized and optimized routine, which is significantly different from a merely bureaucratic management.

\section{Some Correlations with the " $6 \mathrm{R}+\mathrm{NY}$ " Management Model}

Seeking to deepen the conceptual consistency of the "6R+NY" Model, Fig. 2 shows one more correlation between it and the MEPM (Model of Excellence in Public Management), explained in a dual PDCA. An also, Fig. 2 displays a connection to the MSAG, other proposed model, as a system for the management assessment [5].

The " $6 \mathrm{R}+\mathrm{NY}$ " Model is rooted in GST (General Systems Theory). "Everything in this world is a system. The systems interact to a greater or lesser degree and all of them are interconnected. There is no way to manage an organization knowing these relationships. This is systems thinking" [4]. In light of 
this theory and aiming to embody this model sought to associate each "R" and "N" to certain types of ongoing management in organizations.

(R1) Results: Quality Management; Strategic Management; Routine Management; Financial Management and so on.

(R2) Resources: Cost Management; Space Management; Logistics Management and so on.

(Y) Yields: Process Management; Technology Management; Innovation Management and so on.

(R3) Relationship: Personnel Management; Relationship with Stakeholders and so on.

(N) Network: Knowledge Management; Learning Management; Intellectual Capital Management and so on.

(R4) Residues: Environmental Management; Losses and Entropy Management; Reverse logistic and so on.

(R5) Responsibility: Social Management; Cultural Management and so on.

(R6) Rapidity: Time Management; Opportunities Management; Decisions Management and so on.

It should be noted that the above correlation follows a perspective of GST, in which each part of the whole is a function of the other. Thus, the model reveals a matrix in which the management of each " $\mathrm{R}$ ", " $\mathrm{N}$ " or "Y" is interdependent with others: each factor crosses, permeates, interpenetrates, and mutually interacts with each other [8].

$$
\begin{aligned}
& R 1=f(R 2+Y+R 3+N+R 4+R 5+R 6) \\
& R 2=f(R 1+Y+R 3+N+R 4+R 5+R 6) \\
& Y=f(R 1+R 2+R 3+N+R 4+R 5+R 6) \\
& R 3=f(R 1+R 2+Y+N+R 4+R 5+R 6)
\end{aligned}
$$

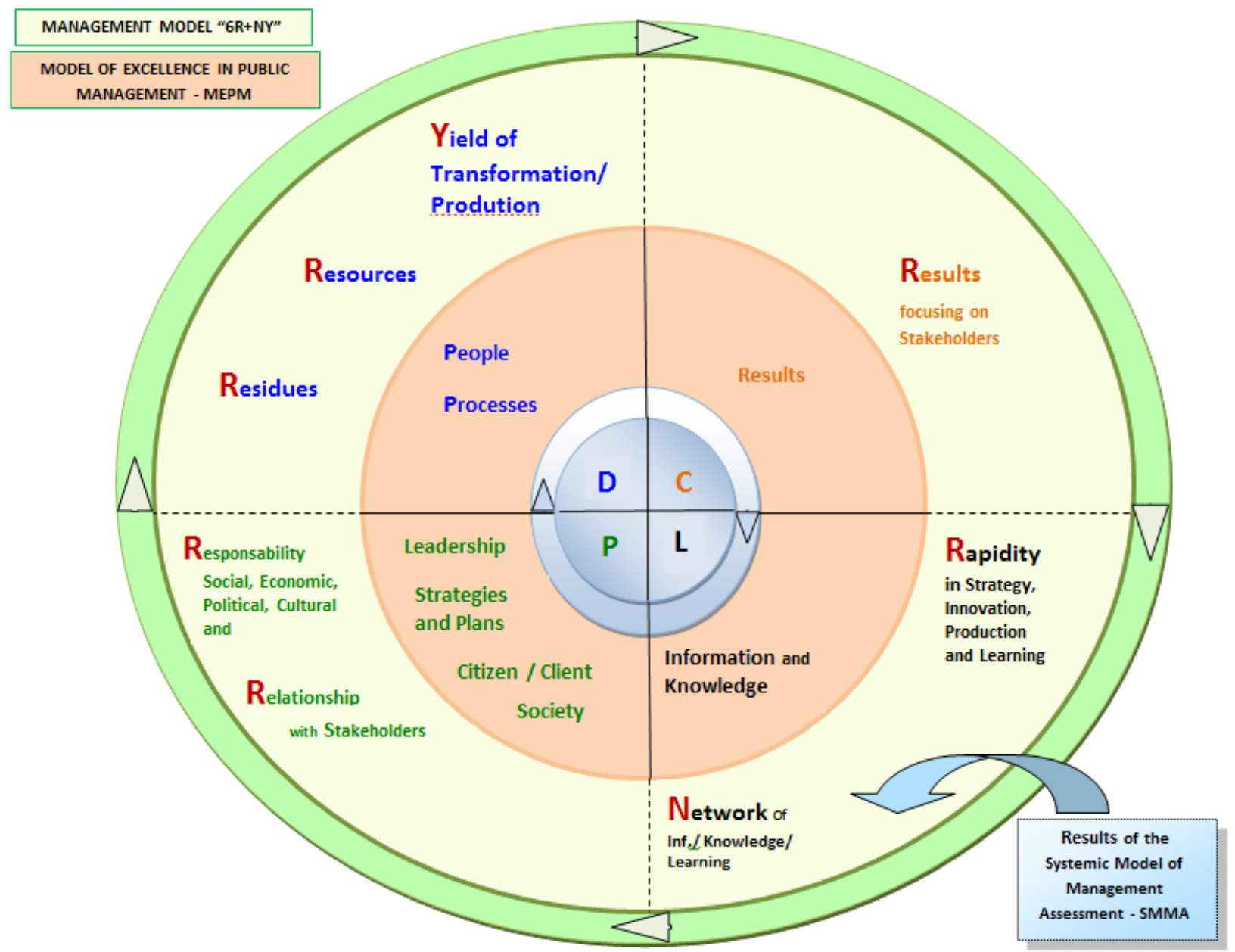

Fig. 2 Correlation between eight management dimensions $(6 \mathrm{R}+\mathrm{NY})$ and the criteria for excellence of MEM/MEPM in the configuration PDCL. 


$$
\begin{aligned}
& \mathrm{N}=\mathrm{f}(\mathrm{R} 1+\mathrm{R} 2+\mathrm{Y}+\mathrm{R} 3+\mathrm{R} 4+\mathrm{R} 5+\mathrm{R} 6) \\
& \mathrm{R} 4=\mathrm{f}(\mathrm{R} 1+\mathrm{R} 2+\mathrm{Y}+\mathrm{R} 3+\mathrm{N}+\mathrm{R} 5+\mathrm{R} 6) \\
& \mathrm{R} 5=\mathrm{f}(\mathrm{R} 1+\mathrm{R} 2+\mathrm{Y}+\mathrm{R} 3+\mathrm{N}+\mathrm{R} 4+\mathrm{R} 6) \\
& \mathrm{R} 6=\mathrm{f}(\mathrm{R} 1+\mathrm{R} 2+\mathrm{Y}+\mathrm{R} 3+\mathrm{N}+\mathrm{R} 4+\mathrm{R} 5)
\end{aligned}
$$

The " $6 \mathrm{R}+\mathrm{NY}$ " Model, such as GST, understands an organization as a system composed of interacting and interdependent parts, which together should form a whole, with particular purpose and function [5]. According to GST, each of the elements behaves, in turn, as a system whose result is greater than the result that the units could be worked independently [8].

\section{Conclusions}

From the foregoing, it can be said that the "6R+NY" Management Model while modeling exercise initially directed to the Federal Network formed by high schools in Brazil, could be customized for different organizations, in a proactive and modern perspective. In addition to being bonded to the GST and the concepts of modeling and models [5], this model systematized the practical experience of over 30 years of the authors in this field. The " $6 \mathrm{R}+\mathrm{NY}$ " model evidenced thus relationships and possible causalities between interdependent variables present in the different organizational contexts. The " $6 \mathrm{R}+\mathrm{NY}$ " management model intends to expand the focus and enrich the practice of management, favoring a systemic view to facilitate the implementation of improvements in everyday action of its operations and strategies.

\section{References}

[1] Stanford Encyclopedia of Philosophy. 2009. Accessed August 30, 2015. http://plato.stanford.edu/entries/ model-theory/.

[2] Suppes, P., Pavel, M., and Falmagne, J. C. 1994. "Representations and Models in Psychology." In Annual Review of Psychology 45: 517-44. Accessed on August, 26, 2015. http://www.annualreviews.org.

[3] Dye, T. R. 2005. "Models of Politcs: Some Help in Thinking about Public Policy." Unserstandig Public Policy. New Jersey: Prentice-Hall, 11-30.

[4] Campos, V. F. 2009. The True Power: Management Practices that Lead to Revolutionary Results. Nova Lima: INDG. Quotes: 28-129.

[5] Almeida, N. A. C. 2013. "Modeling of Organizational Management in a Multidisciplinary and Systemic Approach: Proposals for the Federal Network of Professional Education, Science and Technology-RFEPCT." Ph.D. thesis, Federal University of Bahia.

[6] Stoker, G. 2006. "Public Value Management: A New Narrative for Nertworked Governanace?" Americam Review of Public Administration 36 (1): 41-57.

[7] Bauman, Z. 2001. Liquid Modern. Rio de Janeiro: Zahar.

[8] Bertalanffy, L. von. 1968. Teoria Geral dos Sistemas. 2nd revised edition, 2006. Rio de Janeiro: Vozes. 